\title{
Controvérsias sobre a macroeconomia de Keynes e seus possíveis fundamentos microeconômicos
}

Controversies about Keynes' macroeconomics e its possible microfoundations

\author{
Adriana Nunes Ferreira (1) \\ (1) Universidade de Campinas
}

\begin{abstract}
This article makes a quick review of the arguments that link the theoretical body of General Theory to the apparatus of imperfect competition - both those that Keynes had a chance to respond to, and some that were recovered many years later. The aim here is to defend a crucial point: Keynes's results did not depend on "microfoundations", understood as the definition of particular market structures. It is intended to show that Keynes, when confronted with the suggestion to use an imperfect competition apparatus to base his results, strongly rejected this possibility, showing that the definition of a specific market structure is not necessary to support his arguments.
\end{abstract}

\section{Keywords}

Keynes; imperfect competition; microfoundations.

JEL Codes 5E; B22.

\section{Resumo}

Este artigo faz rápida revisão dos argumentos que ligam o corpo teórico da Teoria Geral ao aparato de concorrência imperfeita - tanto os que Keynes teve chance de responder, quanto alguns que foram recuperados muitos anos depois. O que se quer, aqui, é defender um ponto crucial: os resultados de Keynes não dependiam de "fundamentos microeconômicos", entendidos como a definição de estruturas de mercado particulares. Pretende-se mostrar que Keynes, ao ser confrontado com a sugestão de utilizar um aparato de competição imperfeita para fundamentar seus resultados, rejeitou fortemente esta possibilidade, mostrando não considerar necessária, para a sustentação de seus argumentos, a definição de uma estrutura de mercado específica. Mais tarde, várias críticas feitas à Teoria Geral em seu berço foram retomadas.

\section{Palavras-chave}

Keynes; concorrência imperfeita; fundamentos microeconômicos.

Códigos JEL 5E; B22. 


\section{Introdução}

A macroeconomia contemporânea do mainstream tornou-se, em muitos aspectos, microeconomia. Os resultados keynesianos de quebra da dicotomia clássica e existência de excesso de oferta no mercado de trabalho são explicados por uma enorme gama de modelos microeconômicos que se assentam em informações, contratos e competição imperfeita. Tais autores procuram especificar em que aspectos os "microfundamentos" devem se distanciar do aparato de equilíbrio geral walrasiano para que se possam derivar aqueles resultados. Este artigo pretende contribuir para a discussão de um aspecto particular da relação entre "fundamentos microeconômicos" e macroeconomia: o da relação entre a definição da estrutura de mercado, em particular de competição imperfeita, e a teoria keynesiana (de Keynes).

Keynes fundou um novo campo de conhecimento, a macroeconomia. Pretendia, em sua Teoria Geral, estudar os determinantes dos agregados econômicos - a renda agregada, o investimento agregado, o consumo agregado, o nível de emprego agregado. Esse, aliás, é um dos significados que ele atribui ao termo "geral" de sua obra:

No prefácio à edição francesa, lê-se:

Dei à minha teoria o nome de Teoria Geral. Com isso quero dizer que estou preocupado principalmente com o comportamento do sistema econômico como um todo - com a renda global, com o lucro global, com o volume global da produção, com o nivel global do emprego, com o investimento global e com a poupança global, em vez de com a renda, o lucro, o volume da produção, o nivel de emprego, o investimento e a poupança de ramos da indústria, firmas ou indivíduos em particular. E afirmo que foram cometidos erros importantes ao se estender para o sistema como um todo as conclusões a que se tinha chegado de forma correta com relação a uma parte desse sistema tomado isoladamente. (Keynes, 1988, p. 16, grifo nosso).

O desemprego involuntário era para ele um problema social a ser explicado e enfrentado em bases radicalmente distintas daquelas colocadas pelo que ele chamava "teoria clássica". Na sua visão, o nível de emprego não era determinado no âmbito do mercado de trabalho, como defendiam seus antecessores. Resultava dos cálculos dos donos da riqueza, em condições de incerteza. A distinção feita por Keynes entre economia cooperativa e economia empresarial, nos textos preparatórios à Teoria Geral, revela o que ele entendia como seu objeto de estudo: ${ }^{1}$

1 Neste artigo, em que são utilizadas várias citações provindas dos Collected Writings de Keynes ou de Kalecki ainda não traduzidas para o português, escolheu-se deixar os originais 
A lei da produção em uma economia empresarial pode ser colocada da seguinte forma. Um processo de produção não será iniciado a menos que os resultados monetários esperados da venda do produto sejam no minimo iguais aos custos monetários que poderiam ser evitados se tal processo não fosse iniciado. (Keynes, 1979, p. 78).2

A firma somente negocia em termos de montantes de dinheiro. Ela não tem outro objetivo no mundo exceto terminar com mais dinheiro do que quando começou. Esta é a característica essencial de uma economia empresarial. (Keynes, 1979, p. 89)..$^{3}$

Esse era o traço distintivo da economia de Keynes: ele tratava dos resultados agregados de tomadas de decisão dos proprietários da riqueza. E o objetivo desses proprietários de riqueza não era outro a não ser acumular riqueza. Essa era para Keynes a essência de uma economia capitalista. ${ }^{4}$

Nesse mundo que Keynes desvendava, o dinheiro não era apenas, como para seus antecessores, um véu. Faz parte da essência de uma economia "empresarial" (de "entrepreneur") ser, também, uma economia monetária. Nessa versão do capítulo dois dos esboços da Teoria Geral datados de 1933, Keynes deixava esse ponto claro. Na versão de 1936, o leitor só ganha plena compreensão desta visão ao ler o capítulo dezessete, sobre as propriedades essenciais do juro e do dinheiro. $O$ dinheiro, para Keynes, fazia parte do conjunto de ativos que os agentes desejavam. Dinheiro enquanto tal, ativo cuja demanda não poderia ser facilmente contida, que não era passível de ser produzido por trabalho e que servia aos proprietários da riqueza como refúgio contra a incerteza.

Dinheiro é por excelência o meio de remuneração em uma economia empresarial em que se verificam flutuações na demanda efetiva. Mas se empregadores remunerassem seus trabalhadores em termos de terra ou Torr (1980) faz uma excelente resenha do volume 29 dos Collected Writings de Keynes, destacando a distinção - expressa nesses escritos - entre uma economia empresarial e uma economia cooperativa. selos postais em desuso, as mesmas dificuldades poderiam surgir. Talvez, qualquer coisa em termos da qual os fatores de produção contratados possam ser remunerados, que não seja ou possa ser parte do produto

em notas de rodapé, para que se possa apreciar o sabor (muitas vezes, a contundência) da linguagem dos autores. As traduções aqui apresentadas são de nossa autoria.

2 "The law of production in an entrepreneur economy can be stated as follows. A process of production will not be started up, unless the money proceeds expected from the sale of the output are at least equal to the money costs which could be avoided by not starting the process". (Keynes, 1979, p. 78).

3 "The firm is dealing throughout in terms of sums of money. It has no object in the world except to end up with more money than it started with. That is the essential characteristic of an entrepreneur economy". (Keynes, 1979, p. 89).

4 Torr (1980) faz uma excelente resenha do volume 29 dos Collected Writings de Keynes, destacando a distinção - expressa nesses escritos - entre uma economia empresarial e uma economia cooperativa. 
corrente, seja, de um certo modo, dinheiro. Se assim for, mas somente se assim for, o uso do dinheiro é uma condição necessária para flutuações na demanda efetiva. (Keynes, 1979, p. 81). ${ }^{5}$

Keynes faz, assim, uma outra distinção fundamental entre uma "real exchange economy" e uma economia monetária:

Uma economia que usa dinheiro, mas que o usa meramente como uma ligação neutra entre transações de coisas e ativos reais e não the permite penetrar em motivações e decisões, pode ser chamada - na falta de um nome melhor - uma economia de trocas reais. A teoria que eu proponho trata, em contraposição a isto, de uma economia na qual o dinheiro tem papel próprio e afeta motivos e decisões eé, em resumo, um dos fatores importantes da situação, de forma que o curso dos eventos não pode ser predito, no longo ou no curto prazos, sem o conhecimento do comportamento entre o primeiro e o último estágio. E isto é o que queremos dizer quando falamos de uma economia monetária. (1973c, p. 408). ${ }^{6}$

Nesse contexto - de uma economia "empresarial" ou uma economia "monetária" - a ocorrência de desemprego involuntário resulta das decisões dos proprietários da riqueza, e não da interação dos agentes atuantes no mercado de trabalho. Somente em um caso particular os cálculos de maximização de rendimentos esperados levariam ao pleno emprego, somente nesse caso a teoria clássica conduziria aos mesmos resultados que a sua. A teoria de Keynes pretendia examinar o caso geral, a determinação de qualquer que fosse o nível de emprego. Este, aliás, é um segundo significado do termo "geral" atribuído à Teoria Geral - significado apresentado no capítulo primeiro de sua obra: "Argumentarei que os postulados da teoria clássica se aplicam apenas a um caso especial e não ao caso geral, pois a situação que ela supõe acha-se no limite das possíveis situações de equilíbrio". (Keynes, 1988, p. 21).

Com a publicação da Teoria Geral, Keynes apresentou uma teoria geral e revolucionária, que versava sobre um mundo no qual poderia ocorrer equilíbrio com desemprego involuntário, como resultado da rationale dos pro-

5 "Money is par excellence the means of remuneration in an entrepreneur economy which lends itself to fluctuations in effective demand. But if employers were to remunerate their workers in terms of lands or obsolete postage stamps, the same difficulties could arise. Perhaps anything in terms of which the factors of production contract to be remunerated, which is not and cannot be a part of current output, is, in a sense, money. If so, but not otherwise, the use of money is a necessary condition for fluctuations in effective demand". (Keynes, 1979, p. 81).

6 "An economy, which uses money but uses it merely as a neutral link between transactions in real things and real assets and does not allow it to enter into motives and decisions, might be called - for want of a better name - a real exchange economy. The theory which I desiderate would deal, in contradiction to this, with an economy in which money plays a part of its own and affects motives and decisions and is, in short, one of the operative factors in the situation, so that the course of events cannot be predicted, either in the long period or in the short, without a knowledge of the behaviour between the first state and the last. And this is which we ought to mean when we speak of a monetary economy". (1973c, p. 408). 
prietários de riqueza tomando suas decisões em um ambiente de incerteza.

A publicação da Teoria Geral foi cercada de muitos debates - inicialmente, dentro do próprio circuito de Cambridge. Desde seu berço, essa obra enfrentou críticas que versavam sobre o que se poderia chamar de microfundamentos da Teoria Geral. Uma primeira vertente da discussão sobre "microfundamentos" veio de autores que concordavam com a mensagem teoricamente revolucionária de Keynes - notadamente, Joan Robinson e Kalecki -, mas que defendiam que a incorporação de um aparato microeconômico baseado em concorrência imperfeita fosse necessária ou, no mínimo, muito enriquecedora.

Este artigo faz rápida revisão desses argumentos que ligam o corpo teórico da Teoria Geral ao aparato de concorrência imperfeita - tanto os que Keynes teve chance de responder, quanto alguns que foram recuperados muitos anos depois. O que se quer, aqui, é mostrar que Keynes argumentou contundentemente que seus resultados não dependiam de "fundamentos microeconômicos", entendidos como a definição de estruturas de mercado particulares. Com efeito, Keynes, ao ser confrontado com a sugestão de utilizar um aparato de competição imperfeita para fundamentar seus resultados, rejeitou fortemente esta possibilidade, mostrando não considerar necessária, para a sustentação de seus argumentos, a definição de uma estrutura de mercado específica. Mais tarde, várias críticas feitas à Teoria Geral em seu berço foram retomadas.

Na próxima seção, apresenta-se o debate entre Keynes e seus contemporâneos. A terceira seção dedica-se à retomada deste tema por vários economistas keynesianos. Seguem-se algumas conclusões.

\section{0 debate nos anos 30}

Há várias passagens, nas correspondências de Keynes, que mostram o que ele pensava da hipótese de competição imperfeita. Uma particularmente saborosa foi uma troca de cartas entre ele e Joan Robinson, ocorrida entre fevereiro e março de 1941, a respeito de um artigo submetido por Kalecki ao The Economic Journal - que, diga-se de passagem, acabou rejeitado por

7 Lamentavelmente, se houve troca de cartas sobre este artigo diretamente entre Keynes e Kalecki, esta não foi recuperada. O referido artigo denomina-se "A Theorem of Technical Progress", e foi publicado na The Review of Economic Studies, ainda em 1941. Para uma análise da 
Keynes. Nas páginas iniciais, Kalecki estabelece as hipóteses de seu artigo. Uma delas é a de que as firmas trabalham com curvas de custo marginal de curto prazo horizontais, operando abaixo da capacidade máxima. Este foi um dos motivos da péssima avaliação do artigo por parte de Keynes, que chega a qualificá-lo de "elevado, quase delirante nonsense" (1983, p. 829).8

Com efeito, se Kalecki pretendia tratar de problemas de longo prazo, como era possível que ele assumisse que as firmas operassem abaixo da plena capacidade? Joan Robinson sai em defesa de Kalecki e afirma: "quanto à operação abaixo da plena capacidade, esta é parte dos truques usuais da Teoria da Competição Imperfeita. Afirmar que normalmente os preços excedam os custos marginais diretos parece suficientemente aceitável, e é praticamente a mesma coisa" (Robinson, 1983, p. 830). ${ }^{9}$

Keynes desqualifica esse aparato como um "esoteric abracadabra", ao que Robinson reage, evidentemente, dizendo que se fosse uma doutrina esotérica era preciso reconhecer que ela já se encontrava em todos os livros-texto. Presenteia, inclusive, seu interlocutor com um didático gráfico retratando uma firma em competição imperfeita (com curva de demanda negativamente inclinada e curva de custo marginal horizontal).

A discussão se encerra, algumas cartas depois, pelo incisivo veredicto do editor do The Economic Journal: "...eu estou inclinado a retornar à opinião de que o artigo é pretensioso, enganador, inconclusivo e, talvez, errado. Eu preferiria ter em queijo o peso que o artigo ocuparia nas 5.000 cópias do Jornal" (Keynes, 1983, p. 836)..$^{10}$

Em outra troca de correspondências, dessa vez com Ohlin, aparece esta mesma falta de disposição em relação ao tema da competição imperfeita. Ohlin tinha enviado um artigo no qual, entre outras coisas, criticava o uso, por parte de Keynes, da demanda por trabalho "ortodoxa", isto é, a curva que relacionava os salários reais à produtividade marginal do trabalho. Esta formulação implicaria, na verdade, a aceitação de que as firmas normalmente operavam sujeitas a retornos decrescentes no curto prazo. Ou

troca de correspondências entre Keynes e Kalecki, ver Asimakopolus (1990).

8 "high, almost delirious nonsense" (1983, p. 829).

9 "As for under-capacity working, that is part of the usual tricks of Imperfect Competition theory. To say that price normally exceeds marginal prime costs sounds commonplace enough, but is usually the same thing." (Robinson apud Keynes, 1983, p. 830).

10 "...I am inclined to return to the opinion that the article is pretentious, misleading, inconclusive and perhaps wrong. I would rather have cheese to a weight equal to the paper it would occupy in 5,000 copies of the Journal" (Keynes, 1983, p. 836). 
seja, um aumento do emprego somente poderia ocorrer com uma queda de salários reais, o que para ele não se coadunaria com um mundo em competição imperfeita, em que as firmas operam com excesso de capacidade.

Diz Ohlin: "Nesta, assim como em outras questões, Keynes não parece ter sido radical o suficiente para libertar-se das hipóteses convencionais. Ao ler o livro, é razoável indagar-se se ele nunca discutiu competição imperfeita com a Sra. Robinson." (Ohlin apud Keynes, 1983, p. 196). ${ }^{11}$

Keynes responde a essas observações aparentemente espantado com a referência de seu interlocutor ao aparato de competição imperfeita: "A referência à competição imperfeita me causa muita perplexidade. Eu realmente não vejo qual a relação. A Sra. Robinson, eu devo dizer, leu meus manuscritos sem descobrir qualquer conexão." (Keynes, 1973a, p. 190). ${ }^{12}$

E, adiante: "Eu tenho considerado a hipótese de retornos físicos decrescentes no curto prazo como uma das poucas proposições incontroversas de nossa miserável matéria!". (...) Eu deveria ter pensado que o emprego nunca caiu efetivamente sem um aumento dos salários reais. Esta não é uma das mais bem estabelecidas conclusões estatísticas?" (Keynes, 1973a, p. 190). ${ }^{13}$

É curioso que Keynes tenha desqualificado com tanta veemência o aparato de competição imperfeita, especialmente quando se leva em conta que, no ambiente de Cambridge dos anos trinta, vários de seus interlocutores tratavam desse novo campo. Em particular, dois de seus mais próximos, Joan Robinson e Richard Kahn. Esse último levantou a ideia de que o ambiente perfeitamente competitivo era incompatível com a presença de firmas operando com excesso de capacidade em períodos de depressão, e que, portanto, não explicava bem o funcionamento da economia em tais circunstâncias. ${ }^{14}$

11 "In this as in some other respects Keynes does not seem have been radical enough in freeing himself from the conventional assumptions. When reading the book one sometimes wonders whether he never discussed imperfect competition with Mrs. Robinson." (Ohlin apud Keynes, 1973a, p. 196).

12 "The reference to imperfect competition is very perplexing. I cannot see how on earth it comes in. Mrs. Robinson, I may mention, read my proofs without discovering any connection". (Keynes, 1973a, p. 190).

13 "I have always regarded decreasing physical returns in the short period as one of the very few incontrovertible proposition of our miserable subject!" (...) "I should have thought that employment never did fall materially without a rise in the real hourly wage. Is not this one of the best established of statistical conclusions?" (Keynes, 1973a, p.190).

14 Kahn desenvolveu esse tema em sua "fellowship dissertation", apresentada em 1929 e editada em Kahn (1989). 
Esse ponto também é levantado por Sawyer (1995, cap. 7), que se coloca uma interessante questão: se Keynes, ao que tudo indica, tomou contato com a "revolução" que ocorria no âmbito da teoria microeconômica e fez questão de - por vezes até de forma não muito delicada - desqualificar seu uso para a análise macroeconômica, talvez fosse porque ele não achasse esse aparato necessário para demonstrar seu ponto. Aqui cabe destacar que mesmo Joan Robinson, em seu Economics of Imperfect Competition (1933), dizia compartilhar essa ideia: "Não há tendência natural, mesmo sob perfeita competição, a manter-se o pleno emprego, o qual depende do nível de poupança e de investimento" (Robinson, 1933 apud Sawyer, 1995, p. 120).

Por outro lado, no artigo "Relative movements of Real Wages and Output" (1939) - cujo objetivo era comentar as pesquisas de Tarshis e Dunlop ${ }^{15}$ acerca da relação entre salários nominais e salários reais - Keynes mostra uma atitude mais receptiva ao que ele denominara "esoteric abracadabra" e considera explicitamente a introdução da hipótese de concorrência imperfeita. Tarshis e Dunlop, a partir de pesquisa empírica realizada com dados dos Estados Unidos e da Inglaterra, mostraram que salários reais e nominais caminhavam na mesma direção quando de uma subida nos salários nominais, enquanto guardavam uma relação indeterminada quando de uma queda dos mesmos.

Esses achados contrariavam, de alguma maneira, a proposição de Keynes de que enquanto as mudanças de salários reais e nominais tendiam a dar-se na mesma direção para uma indústria em particular, isto não se verificava para o nível geral de salários. Keynes, em sua Teoria Geral, explica que quando de uma retração do emprego, ocorreriam tanto uma queda de salários nominais quanto um aumento de salários reais. A primeira aconteceria porque com menor nível de emprego, os trabalhadores perdem poder de barganha sobre salários nominais; e o segundo, porque a queda do emprego seria acompanhada por aumento de retornos marginais. A ideia de que salários reais devessem crescer com a queda do emprego era explicada, portanto, pela vigência do "primeiro postulado" clássico. ${ }^{16}$

15 Os resultados dessas pesquisas para a Inglaterra foram publicados em Dunlop, J. G (1938). 16 Essa argumentação encontra-se no capítulo 2 da Teoria Geral: "No caso de uma variação que afeta apenas certo gênero de indústria, é de se esperar que os salários reais variem no mesmo sentido dos salários nominais. Mas no caso de variações do nível geral de salários, observaríamos, julgo eu, que a variação dos salários reais que acompanha a dos salários nominais, longe de se apresentar normalmente no mesmo sentido, ocorre quase sempre no 
Keynes, nesse artigo de 1939, dedica-se ao reexame da postulação de salários reais contracíclicos. ${ }^{17}$ Inicialmente, recupera a origem de seu argumento. Ele teria como base pressupostos microeconômicos. Eram eles: (a) custos marginais crescentes no curto prazo; (b) custos salariais marginais como boa aproximação dos custos marginais e (c) preços governados por custos marginais.

É de se notar que (a) e (c) são dois pilares da descrição neoclássica do comportamento de custos e preços em concorrência perfeita. Keynes, embora muito reticente quanto à necessidade de examinar esses pressupostos nas correspondências mencionadas nesta seção, faz exatamente este esforço nesse artigo. No que diz respeito à hipótese de custos marginais crescentes no curto prazo, Keynes admite, concordando, curiosamente, com Kalecki, que é possível que não seja válida para níveis de utilização da capacidade muito abaixo dos de pleno emprego. No entanto, mantém-se firme na crença de que, em algum nível da utilização da capacidade produtiva, a curva volte a inclinar-se positivamente:

Mesmo que se concorde que a inclinação da curva de custo marginal de curto prazo é negativa no inicio de sua extensão, a suposição do Sr. Kahn ${ }^{18}$ de que ela, em algum ponto, torne-se positiva, está além de qualquer questionamento sensato; e que, além disto, isto ocorra na parte da curva que é a mais relevante para questões práticas. Seriam, certamente, necessárias evidências mais convincentes do que as já existentes para me persuadir a abdicar de tal pressuposto. (Keynes, 1973b, p. 405). ${ }^{19}$

Keynes acreditava ser necessária a elaboração de estudos estatísticos para determinar o formato da curva de custo marginal, uma vez que este teria

sentido oposto(...) Isso se deve ao fato de que, em um curto período, a baixa dos salários nominais e a elevação dos salários reais constituem, por motivos diferentes, fenômenos ligados à diminuição do emprego, pois, embora o trabalhador se mostre mais disposto a aceitar reduções de salário quando o emprego declina, os salários reais tendem, inevitavelmente, a crescer nas mesmas circunstâncias, em virtude do maior retorno marginal de determinado estoque de capital quando a produção diminui”. (Keynes, 1988, p. 25).

17 Keynes argumenta que essa ideia já estava em Marshall, embora por razões distintas. Este, partindo da ideia de que salários nominais seriam mais rígidos que preços, sugeriu que uma queda de preços (causada, eventualmente, por uma depressão) levaria a um aumento dos salários reais. Keynes comenta que essa ideia foi aceita como um dogma embora estivesse essencialmente equivocada, como o mostrariam estatísticas posteriormente desenvolvidas.

18 Keynes faz aqui referência a artigo de Kahn (1931), "The Relation of Home Investment to Employment", no qual diz ter inspirado sua ideia de salário real contra-cíclico.

19 "Even if one concedes that the course of the short-period marginal cost curve is downwards in its early reaches, Mr. Kahn's assumption that it eventually turns upward is, on general commonsense grounds, surely beyond reasonable questions; and that this happens, moreover, on a part of the curve which is highly relevant for practical purposes. Certainly it would require more convincing evidence than yet exists to persuade me to give up this presumption". (Keynes, 1973b, p. 405). 
impacto significativo sobre os movimentos relativos dos salários nominais e reais. Sua intuição era de que essa relação se modificaria sensivelmente de acordo com o nível de emprego vigente. De qualquer forma, nosso autor reconhece que, nos anos trinta, o nível de emprego estivera tão baixo que, provavelmente, a situação seria melhor descrita como correspondente àquela "antes da inflexão para cima" (p. 406) ${ }^{20}$ da curva de custo marginal.

Keynes faz aqui uma reflexão que é fundamental para a compreensão de sua atitude em relação à competição imperfeita. $O$ argumento de que o salário real seria contracíclico - assentado na hipótese de custos marginais crescentes no curto prazo - era, segundo ele próprio, "inconveniente" para seus propósitos teóricos mais gerais. Com efeito, em suas discussões sobre os efeitos no emprego de uma política expansionista, Keynes tinha que lidar com o fato de sua teoria implicar um salário real menor como corolário de políticas de estímulo à demanda efetiva. Outros autores, contrários "Before the upturn" (Keynes, 1973b, p. 406). à visão expansionista, como Pigou, explicavam esse mesmo salário real contracíclico utilizando uma outra cadeia lógica: políticas de investimento público levariam à inflação, o que - pela corrosão do salário nominal pela inflação - levava à queda do salário real e ao consequente aumento do emprego. O mesmo resultado, para os adversários de Keynes nesse debate, poderia ter sido atingido por uma redução dos salários nominais, sem necessitar de uma política com resultados inflacionários. Keynes reflete que concordar com seus adversários quanto à observação de um salário real contra-cíclico não facilitou sua posição na defesa expansionista.

Conclui o autor:

Se (...) o formato da curva de custo marginal demonstra ser tal que nós tendamos a nos encontrar, em condições como as presentes, mais frequentemente à esquerda do que à direita de seu ponto crítico, o argumento favorável a uma política expansiva planejada é consideravelmente reforçado; neste caso, muitas das limitações para as quais devemos atentar uma vez alcançado este ponto poderiam ser frequentemente negligenciadas. Ao tomar como suposição geral que estejamos frequentemente à direita do ponto crítico, eu tenho assumido o caso no qual a política prática que defendo precisa ser mais cuidadosamente tratada. (Keynes, 19736, p.406, grifo nosso). ${ }^{21}$

20 "Before the upturn" (Keynes, 1973b, p. 406).

21 "If (...), the shape of the marginal-cost curve proves to be such that we tend to be living, with conditions as they are at present, more often to the left than to the right of its critical point, the practical case for a planned expansionist policy is considerably reinforced; for many caveats to which we must attend after this point has been reached can be, in this case, frequently neglected. In taking it as my general assumption that we are often to the right of the critical point, I have been taking the case in which the practical policy which I have advocated needs the most careful handling." (Keynes, 
Ou seja, Keynes argumenta que venceu seus adversários "em seu próprio terreno", no que toca à definição de uma estrutura de mercado, sem necessitar se aventurar no campo (para ele, ainda muito pantanoso) de estruturas distintas das de concorrência perfeita.

Questão mais complexa é a da regra de formação de preços. Keynes se pergunta se é legítimo assumir que, para qualquer nível de utilização da capacidade, os preços se pautam pelos custos marginais. Nesse ponto, admite que é bastante razoável que a política de preços, em condições de competição imperfeita, seja mais influenciada pelos custos médios de longo prazo do que pelos custos marginais. Diz ele:

(...) os produtores são influenciados, em suas políticas práticas e na exploração das oportunidades obtidas através de imperfeições da competição, pelos seus custos médios de longo prazo, e são menos atentos do que os economistas a seus custos marginais de curto prazo. De fato, é raro qualquer outro que não um economista supor que os preços sejam governados predominantemente por custos marginais. (Keynes, 19736, p. 407).22

Como os produtores normalmente operam com custos médios de longo prazo decrescentes, eles podem, quando o produto cresce, manter preços ou fazê-los subir menos do que seria necessário para compensar custos marginais crescentes. Assim, o resultado seria um salário real pro-cíclico. Isso se coadunaria, observa ele, com as evidências estatísticas de que o lucro por unidade tende a se manter constante (ou diminuir) quando cresce o produto. Sobre isso, aliás, cita o artigo de Kalecki ("um brilhante artigo publicado na Econometrica"), em que analisa a distribuição do produto entre os fatores sob condições de competição imperfeita. ${ }^{23}$

Keynes admite:

Independentemente do que uma investigação mais completa do problema possa trazer, é evidente que o Sr. Dunlop, o Sr. Tarshis e o Dr. Kalecki deram-nos muito em que pensar e abalaram seriamente as suposições fundamentais sobre as quais a teoria da distribuição de curto prazo tem se baseado até aqui; - parece que, para propósitos práticos, seria preferivel adotar um conjunto diferente de simplificações do que aquele assumido até aqui.

E, adiante, conclui:

1973b, p. 406, grifo nosso).

22 "(...) Insofar as producers are influenced in their practical policies and in their exploitation of the opportunities given by them by the imperfections of competition, by their long-period average cost, and are less attentive than economists to their short-period marginal costs. Indeed, it is rare by anyone but an economist to suppose that price is predominantly governed by marginal costs." (Keynes, 1973b, p. 407).

23 Kalecki, M. (1938). 
Por enquanto eu estou confortado pelo fato de que suas conclusões tendam a confirmar a ideia de que as causas de flutuações de curto prazo devam ser encontradas em variações da demanda por trabalho, e não em variações de seu preço real de oferta. (Keynes, 1973b, p. 411). ${ }^{24}$

De fato, se salários reais não são contracíclicos, então uma expansão do emprego tem como causa um aumento da demanda por trabalho - que, como sabemos, para ele era uma demanda derivada, oriunda de cálculos de alocação da riqueza feitos em outros mercados - e não, como queria Pigou (1933), uma queda dos salários reais.

Em síntese, se nas correspondências que se seguiram à publicação da Teoria Geral, Keynes rejeitou veementemente a possibilidade de incorporar a hipótese de competição imperfeita na explicação da determinação do nível geral de emprego, mostrando até mesmo, em certos trechos, algum desprezo por tal aparato, nesse artigo ele considera a hipótese válida para o entendimento do comportamento dos salários reais diante de uma expansão do produto. No entanto, fica claro que ele não considera tal hipótese necessária para chegar aos seus resultados ou para provar seus argumentos.

Uma ressalva da maior importância se faz necessária. Embora o argumento aqui avançado seja de que o próprio Keynes percebia seu aparato macroeconômico como prescindindo da definição de estruturas específicas de mercado, seu aparato teórico não se coaduna com o aparato teórico neoclássico de concorrência perfeita: um aparato atomista, com agentes dotados de racionalidade substantiva, que tem como objetivo a maximização de lucros advindos da produção por parte das firmas e da utilidade advinda do consumo por parte dos consumidores. ${ }^{25}$ Não há lugar para moeda, nem é o objetivo de "mais dinheiro" o que move sistema - como vimos ser o caso no que ele denomina de "economia monetária". No mundo de Keynes, os agentes tomam suas decisões em condições de incerteza, e levam para tanto as decisões dos demais, também incertas. E sabem incertos os resultados

24 "Whatever a more complete inquiry into the problem may bring forth, it is evident that Mr Dunlop, Mr. Tarshis and Dr. Kalecki have given us much of think about, and have seriously shaken the fundamental assumptions on which the short-period theory of distribution has been based hitherto; - it seems that for practical purposes a different set of simplifications from those adopted hitherto are preferable." "Meanwhile I am comforted by the fact that their conclusions tend to confirm the idea that the causes of short-periods fluctuations are to be found in changes in the demand for labour, and not in changes in its real-supply price." (Keynes, 1973b, p. 411).

25 Lavoie (2014), em seu capítulo 1, faz uma excelente síntese dos pressupostos metodológicos das escolas "Heterodoxas" versus os das escolas "Ortodoxas". As leituras pós-keynesianas de Keynes caberiam na primeira categoria, enquanto as escolas de orientação neoclássica na segunda. Há enorme literatura sobre o tema da distinção do método de Keynes em relação ao dos neoclássicos, mas infelizmente mergulhar nessa discussão foge ao escopo deste artigo. 
da interação de suas decisões. A incerteza confere à moeda um lugar fundamental nesse aparato, como um receptáculo de riqueza que serve como refúgio contra ela aos proprietários de riqueza, e o desemprego é parte inerente ao funcionamento de uma economia com tais caraterísticas.

Talvez, o próprio Keynes tenha aberto a porta para muitos dos desdobramentos posteriores à publicação da Teoria Geral, em particular as suas leituras neoclássicas - consubstanciadas, em um primeiro momento, na síntese neoclássica e, mais de cinquenta anos depois, no aparato novokeynesiano - ao não levar às últimas consequências suas críticas ao aparato de concorrência perfeita. Ou seja, defender a compatibilidade de seu aparato macroeconômico com qualquer estrutura de mercado, ao mesmo tempo em que consistiu em uma estratégia de defesa da robustez de seus resultados macroeconômicos, fragilizou sua teoria e abriu uma brecha importante para que leituras extremamente empobrecedoras fossem feitas adiante.

O tratamento do fenômeno de desemprego involuntário é uma boa lente para examinar os desdobramentos das leituras neoclássicas de Keynes. Passados mais de cinquenta anos da publicação da Teoria Geral de Keynes, os keynesianos que chegaram ao mainstream da teoria macroeconômica têm posições muito diferentes daquele que lhes emprestou o nome. Em seu mundo, há espaço para a quebra da dicotomia clássica, ou a não neutralidade da moeda, apenas no curto prazo. No longo prazo, as rigidezes ou as deficiências informacionais são eliminadas e a neutralidade da moeda passa a reinar.

Embora, de fato, procurem entender a existência de pessoas desempregadas, sua explicação para este fenômeno centra-se fundamentalmente na existência de formas de rigidez - em última instância, situadas no mercado de trabalho - que impedem o salário real de cair de modo a se ajustar à produtividade marginal do trabalho correspondente ao pleno emprego. ${ }^{26}$

Como esses autores explicam a existência de rigidez de salários reais? Pela própria racionalidade maximizadora das firmas - ou da dos trabalhadores. Ou seja: a explicação da existência de desemprego confina-se ao âmbito do mercado de trabalho. Não é, como queria Keynes, o resultado de uma deficiência de demanda, resultado dos cálculos de valorização da riqueza capitalista, mas a decorrência da racionalidade dos agentes comprador e vendedor da força de trabalho.

26 Note-se que esta explicação do desemprego se parece muito com aquela dada pelos antecessores de Keynes. 
O contraste com a posição de Keynes dificilmente poderia ser maior. Para ele, o desemprego involuntário decorre, em última instância, da própria existência da moeda, bem não produtível por trabalho, ativo cuja taxa de retorno é mais resistente à queda do que a de todos os demais - e cuja existência pode eliminar a produção vantajosa dos bens que mobilizam trabalho para tal. Assim, uma queda do nível de salários não leva a economia ao nível de pleno emprego, pois há uma deficiência básica de demanda, inerente ao funcionamento normal de uma economia de mercado. É isso que faz do desemprego de Keynes um problema macroeconômico, e é isso que o faz involuntário: o nível de emprego (e desemprego) da economia não é determinado no âmbito do mercado de trabalho, mas em outros mercados, nos quais os capitalistas tomam suas decisões de investimento. Assim, mesmo que os trabalhadores aceitem uma redução nos seus salários nominais (que são, aliás, a única variável em jogo nas negociações salariais), isso não lhes garantiria acesso a postos de trabalho. ${ }^{27}$ Há, em outros termos, uma assimetria básica de poder entre os agentes compradores e vendedores da força de trabalho: somente os primeiros determinam a quantidade que será transacionada.

Davidson (1998), aponta para essa assimetria entre agentes compradores e vendedores da força de trabalho:

\begin{abstract}
Numa economia monetária, trabalhadores desempregados não têm mecanismos disponiveis para induzir empreendedores a modificarem suas decisões de produçãa, de fixação de preço, de demissão e de contratação de trabalhadores adicionais, enquanto as expectativas de maximização de lucro dos empreendedores estiverem sendo satisfeitas.(...) Trabalhadores desempregados desapontados, podem, portanto, reduzir salários monetários até que estejam à mingua [blue in the face] sem alterar um iota a "correta" decisão de contratação do empreendedor que maximiza lucro, a menos que os salários monetários induzam um aumento (deslocamento para cima) da função $D$ denominada em unidades de salário.(Davidson, 1998, p. 825-826)
\end{abstract}

Tudo isso faz do mercado de trabalho um mercado particular, que não pode ser tratado como se trata um mercado qualquer operando em concorrência perfeita. Na verdade, indo mais a fundo, faz com que a lógica marginalista não se aplique à determinação do nível de emprego da economia.

27 No capítulo 19 de sua Teoria Geral, Keynes dedica-se a investigar as repercussões sobre o nível de emprego de variações nos salários nominais. Uma vez que o nível de emprego depende do da demanda efetiva, o autor se pergunta em que medida uma queda nos salários nominais afeta os determinantes desta - a saber, a eficiência marginal do capital, a taxa de juros e a propensão a consumir. $O$ autor investiga sete possíveis efeitos e conclui que os resultados são ambíguos e, em boa medida, imprevisíveis. 


\section{A retomada do debate}

Várias críticas feitas à Teoria Geral em seu berço, sobre a relação entre concorrência imperfeita e o seu arcabouço teórico, ressurgiram no debate contemporâneo.

Marris, convidado a participar do interessante exercício de elaborar uma "Segunda Edição da Teoria Geral" ${ }^{28}$ escreveu o capítulo intitulado "Yes, Mrs. Robinson! - The General Theory and Imperfect Competition". Nesse artigo, argumenta que a Teoria Geral deveria ser revisada incorporando a hipótese de concorrência imperfeita: "Afirmamos que a teoria macro baseada na concorrência perfeita seja inerentemente frágil. Por outro lado, quando se assume competição não-perfeita, a teoria macro torna-se robusta." (Marris, 1997, p. 52).

Marris é enfático ao afirmar que a macroteoria deveria ser elaborada com base em microfundamentos em que firmas operassem em ambiente de concorrência não-perfeita. Para demonstrar o argumento, constrói dois modelos alternativos - um partindo da hipótese de concorrência perfeita e o outro supondo um polipólio ${ }^{29}$ imperfeito. Demonstra que o primeiro modelo só leva a resultados keynesianos - no caso, a existência de desemprego involuntário - quando são supostas o que ele chama de "expectativas irracionais", ou seja, quando os salários são flexíveis, mas as firmas não sabem disso. ${ }^{30}$ Apenas no caso do segundo modelo, o resultado seria, inequivocamente, keynesiano, uma vez que a resposta, desta vez racional, a um declínio da demanda pelo produto de uma firma em competição im-

28 Harcourt, G. C.; Riach, P. A. (eds.), 1997.

29 Termo cunhado por Chick (1983). Para Chick (1983), a "teoria da firma" implícita na formulação de Keynes não se enquadra na tipologia encontrada comumente nos manuais de microeconomia: "a firma representativa de Keynes é uma anomalia do ponto de vista do pensamento estabelecido: é uma pequena firma atomista ou "polipólica" que opera em condições de incerteza e não é, portanto, tomadora de preços." (p.24-25).

30 Nesse modelo, uma queda da demanda nominal agregada levaria a um deslocamento para a esquerda da curva de demanda para cada indústria. O consumo cai, os estoques crescem, caem os preços. O resultado sobre o nível de produto depende da dinâmica dos ajustamentos de preços-salários (na verdade, depende da relação entre preços e salários). Na presença de "expectativas irracionais" por parte das firmas, quando os preços caem, as firmas reduzem a produção - por não saberem que os salários, flexíveis que são, também cairão. Quando percebem isso, as firmas restauram o nível original de produto, mas a demanda agregada real agora já não sustenta esse nível (em decorrência da queda do nível de atividade, a demanda agregada nominal tomou uma trajetória descendente), e então caem o produto e o nível de preços. O resultado é um produto oscilante, e uma trajetória de preços e salários nominais declinante. Uma situação, em outros termos, de "desequilíbrio keynesiano persistente". 
perfeita seria a manutenção dos preços com uma redução proporcional de produto e emprego. ${ }^{31}$ Isso tornaria a Teoria de Keynes mais robusta, uma vez que, mesmo sob a suposição de "expectativas racionais", um choque de demanda levaria a uma queda de produção e emprego.

É evidente que o que Marris chama de "expectativas irracionais", também poderia ser chamado de "maneira racional de formar expectativas em condições de incerteza". Esse autor coloca como condição necessária para a obtenção do resultado "keynesiano" de desemprego involuntário, na suposição de concorrência perfeita, a hipótese de que as firmas não saibam que os salários são flexíveis. No entanto, no esquema analítico desenvolvido na Teoria Geral, mesmo que as firmas soubessem que os salários são flexíveis, elas não saberiam a priori quanto iriam cair os preços e tampouco como comportar-se-iam os preços relativos no processo deflacionário. Além disso, mesmo supondo que a queda dos preços fosse proporcional à dos salários nominais, deixando os salários reais inalterados, haveria que se levar em conta todos os outros fatores desenvolvidos em seu capítulo 19 (redistribuição da renda, ônus da dívida, etc.). ${ }^{32}$ De fato, Keynes ali trabalha com um cenário em que os produtores não sabem quão flexíveis são os salários, e não sabem qual é o efeito potencial de uma redução desses salários sobre a demanda agregada. Então, têm que apostar. É essa "aposta" que causa flutuações no investimento e, portanto, do nível de emprego. Esse é o ponto: a teoria de Keynes não foi construída supondo expectativas "irracionais". A incerteza é parte constitutiva de todo seu esquema analítico.

Sardoni (1996) parte em uma direção distinta, criticando a formulação da eficiência marginal de Keynes. Seu ponto é que a teoria do investimento expressa na Teoria Geral não se sustenta sem que se saia do mundo de concorrência perfeita: "Eu sustento que a eficiência marginal do capital decrescente é baseada em uma estrutura analítica que não pode demonstrar a possibilidade de equilíbrio com desemprego" (Sardoni, 1996, p. 93).

$\mathrm{Na}$ construção de seu argumento, ele recupera as críticas que Kalecki havia endereçado a Keynes, precisamente acerca de sua formulação da eficiência marginal do capital. Uma rápida recuperação desse debate pode ser útil para a compreensão da crítica - e sugestão - de Sardoni.

31 No caso deste modelo, as firmas operam com custo marginal constante. Assim, o deslocamento horizontal da curva de demanda não altera o mark-up.

32 Devo essa observação ao prof. Antonio Carlos Macedo e Silva. 
A primeira crítica de Kalecki (1990) a Keynes ${ }^{33}$ era que a teoria de Keynes somente explicava o nível de investimento ex post, mas não o ex ante. Nos diz Kalecki, sobre a formulação de Keynes da eficiência marginal do capital:

Isto não nos diz nada sobre a esfera das decisões de investimento do empresário, que faz seus cálculos em "desequilibrio" tendo como base os preços de mercado existentes dos bens de investimentos. Isto somente mostra que, se a rentabilidade esperada, calculada a partir deste nivel de preços, não for igual à taxa de juros, uma variação no nivel de investimento deve ocorrer. Isso transformará a situação existente em outra, na qual a rentabilidade esperada iguala-se à taxa de juros. Usando a terminologia dos economistas suecos, pode-se dizer que a teoria de Keynes somente determina o nivel de investimento ex post, mas não diz nada sobre seu nivel ex ante. (Kalecki, 1936, p. 230). ${ }^{34}$

Em segundo lugar, a teoria do investimento de Keynes seria "estática", uma vez que não levaria em conta o efeito da elevação do investimento sobre as expectativas de lucros dos empresários e, portanto, sobre o nível de investimento: o aumento do nível de investimento provoca não somente um aumento dos preços dos bens de investimento, mas também um maior nível de renda. Isso, por sua vez, tende a provocar um aumento de preços em todos os setores, o que eleva as expectativas de ganho por parte dos empresários. Assim, a tendência seria, de novo, uma elevação da diferença entre a eficiência marginal do capital e a taxa de juros. Desse modo, ocorreria, novamente, uma elevação do nível de investimento: "O 'equilíbrio', então, não é atingido, e o aumento do investimento ainda persistirá (aqui nós estamos lidando, como pode facilmente ser visto, com um processo cumulativo Wickselliano)" (Kalecki, 1990, p. 231).35

Importa notar que, em troca de correspondências com Kalecki acerca do artigo "a Theory of the Business Cycle", que este publicara havia pouco na Review of Economic Studies, Keynes comenta esta visão acerca da falta de um limite para o "incentivo a investir", colocada pelo aumento das expectativas de ganho decorrente do aumento dos preços dos bens de investimentos:

33 Kalecki, M. (1990). "Some remarks on Keynes' Theory" in Osiatynski (1990).

34 "It does not say anything about the sphere of investment decisions of the entrepreneur, who makes his calculations in 'disequilibrium' on the basis of existing market prices of investment goods. It only shows that, if the expected profitability, calculated on the basis of this price level, is not equal to the rate of interest, a change in the level of investment will occur. This will transform the existing situation into one in which expected profitability is equal to the rate of interest. Using the terminology of Swedish economists, one can say that Keynes's theory determines only the ex post level of investment, but that it does not say anything about its ex ante level". (Kalecki, 1990, p. 230).

35 "Equilibrium', then, is not reached, and the growth of investment will still persist (we are dealing here, as may easily be seen, with a cumulative Wicksellian process)". (Kalecki, 1990, p. 231). 
No segundo parágrafo completo da página 84, você parece assumir que, não somente o aumento corrente dos preços terá efeitos desproporcionais sobre as expectativas quanto aos preços futuros, mas que se espera que os preços futuros cresçam exatamente na mesma proporção. Certamente esta é uma ênfase exagerada e extravagante dos efeitos da situação imediata (corrente) sobre as expectativas de longo prazo. Parece-me que é somente quando há expectativa de que os preços futuros cresçam na mesma proporção que os preços correntes que se verifica o resultado de que "o equilibrio não é alcançado e o investimento continua a crescer". (Keynes, 1983, p. 793). ${ }^{36}$

A isto Kalecki respondeu que, para resolver o problema do limite ao investimento, haveria que se colocar o "princípio do risco crescente" ou "algo do tipo":

(...) É interessante saber o que determina a taxa de decisões de investimento durante o processo. Eu pensei estar resolvendo este problema ao introduzir o "princípio" do risco crescente (...) eu acredito que a referência ao risco crescente (ou a algo do tipo) é necessária também para uma explicação adequada das várias posições de "equilibrio" (posições nas quais não há tendência de mudança na taxa de investimento). (Kalecki apud Keynes, 1983, p. 795).37

A resposta de Keynes encontra-se em sua própria formulação da eficiência marginal do capital, como ele mesmo observou ao seu interlocutor: "Devo mencionar, de passagem, que o risco relativo ao lucro prospectivo já foi considerado em minha fórmula para a eficiência marginal do capital". (Keynes, 1983, p. 793)..$^{38}$

Sardoni, em sua recuperação da crítica de Kalecki a Keynes, vai bem além do argumento original e propõe uma saída baseada na introdução da hipótese de competição imperfeita, para explicar "por que firmas individuais não expandem sua capacidade indefinidamente" (Sardoni, 1996, p. 103). Somente em um mundo em que as firmas não contam com curvas de demanda perfeitamente elásticas, haveria um limite para a expansão indefinida da capacidade.

Vitoria Chick (2002) retrata o argumento de Sardoni e sai em defesa

36 "In the second complete paragraph on page 84 you seem to be assuming not merely that the current rise of prices will have a disproportionate effect on expectations as to future prices, but that the future prices will be expected to rise in exactly the same proportion. Surely this is an extravagant over-emphasis of the effect of the immediate situation on long term expectations. It appears to me that it is only if future prices are expected to rise in the same proportion as present prices that you have established the result that 'the equilibrium is not reached and the investment continues to rise'". (Keynes, 1983, p. 793).

37 "[...] it is interesting to know what determines the rate of investment decisions during the process. I sought of solving this problem by introducing the 'principle' of increasing risk [...] I think that the reference to increasing risk (or something like that) is necessary also for adequate explanation of various positions of 'equilibrium' (positions in which the rate of investment has no tendency to change)". (Kalecki, 1983, p. 795).

38 "I might mention, in passing, that the risk relating to prospective profit is already allowed for in my formula for the marginal efficiency of capital" (Keynes, 1983, p. 793). 
da teoria do investimento de Keynes, refutando a tese de que a hipótese de concorrência imperfeita seja necessária para a validade do resultado keynesiano de equilíbrio com desemprego:

Tanto Sardoni quanto Kalecki argumentam que, se a eficiência marginal do ca-
pital for maior que a taxa de juros, há um incentivo infinito ao investimento, na
perspectiva das firmas individuais - e, afinal, é nesse âmbito que as decisóes
são tomadas. Ao negar a existência de limites ao investimento lucrativo para as
pequenas firmas, eles rejeitam o argumento que talvez seja a questão central da
Teoria Geral: um limite para as vendas existe até mesmo para as pequenas
firmas. (Chick, 2002, p. 63)

Na teoria do investimento de Keynes, a variável tempo está "embutida" na escala de eficiência marginal do capital. Esta é definida por Keynes nos seguintes termos: "Defino a eficiência marginal do capital como sendo a taxa de desconto que tornaria o valor presente do fluxo de anuidades esperadas desse capital, durante toda a sua existência, exatamente igual ao seu preço de oferta" (Keynes, 1988, p. 101).

O preço de oferta do bem de capital, por sua vez, é definido "não como o preço de mercado, mas como o preço que bastaria, exatamente, para induzir um fabricante a produzir uma nova unidade suplementar desse capital" (p. 101).

Para a tomada de decisão, os agentes comparam a eficiência marginal do capital, variável fortemente expectacional, com a taxa de juros monetária. Quando aumenta o investimento, em dado tipo de capital, a eficiência marginal cai "em parte, porque a renda prospectiva baixará conforme suba a oferta desse tipo de capital e, em parte, porque a pressão sobre as fábricas produtoras daquele tipo de capital causará, normalmente, uma elevação do seu preço de oferta". (p. 101). A curva que relaciona a eficiência marginal do capital ao investimento é, portanto, negativamente inclinada. Chick critica corretamente Sardoni por ter atribuído essa inclinação exclusivamente ao rendimento marginal descrente na produção dos bens de capital - expressa no "segundo fator" mencionado por Keynes - desprezando a limitação advinda da demanda (ou redução da escassez desses bens).

Além disso, convém lembrar que Keynes dá um passo além na construção do conceito de eficiência marginal do capital: propõe a agregação das escalas de eficiência marginal do capital dos diferentes bens de capital, obtendo "uma outra escala, que relacione a taxa de investimento agregado com a correspondente eficiência marginal do capital em geral que aquela taxa de investimento estabelecerá". A esta "nova escala", agregada, Keynes 
chama de "curva de demanda por investimento ou, alternativamente, curva de eficiência marginal do capital" (p.102).

O investimento agregado irá aumentar até o ponto em que "não haja nenhuma classe de bens cuja eficiência marginal do capital exceda a taxa de juros corrente". Seguindo a sugestão de Davidson (1994), pode-se entender esta curva da seguinte forma: realiza-se um ranking das aplicações em bens de capital - as que têm taxas de eficiência marginal do capital superior à taxa de juros são realizadas, as demais, não. Assim é que se determina o nível agregado de investimento.

O próprio Sardoni admite, em uma nota de rodapé, que esta é uma boa solução para o entendimento da curva de eficiência marginal do capital agregada. Embora a formulação de Keynes não explique "satisfatoriamente" a curva de demanda por investimento individual, ela explica a agregada. Mas, se explica o investimento agregado, de alguma forma embute uma explicação sobre como os agentes tomam suas decisões! Eles comparam a taxa monetária de juros à taxa de eficiência marginal do capital. Se a primeira for menor, eles investem, se for maior, não o fazem.

A incerteza permeia a decisão. O ponto é que todas as firmas tomam suas decisões com base em expectativas a respeito de qual será a demanda agregada, bem como sobre as demandas e ofertas das demais firmas. A limitação de demanda é central em uma economia monetária, e esta proposição não depende da estrutura de mercado.

Malcom Sawyer (1995) defende uma posição interessante - e talvez Joan Robinson concordasse com ela: os resultados keynesianos não dependem da hipótese de concorrência imperfeita, mas a Teoria Geral poderia ter se beneficiado muito com a incorporação dessa hipótese. Poderia, inclusive, ter sofrido menos leituras "bastardas" ${ }^{39}$ Em particular, com o aparato de concorrência imperfeita ficam claras as diferenças entre os mercados de produto e de trabalho e torna-se evidente que são os preços dos produtos que estabelecem, ex post, o salário real. Além disso, poderia, também, permitir explicar a existência de firmas operando com excesso de capacidade

39 Aqui, o autor refere-se à curva de demanda por trabalho, que, como muito bem apontado por Davidson (1983) não é igual à curva de produtividade marginal do trabalho no aparato de Keynes (os salários reais e o nível de emprego não são determinados, como sugeriria a análise neoclássica, pela demanda e oferta de trabalho). A derivação de uma relação não negativa entre salários reais e emprego poderia ter permitido a Keynes negar o primeiro postulado clássico que, segundo muitos - notadamente, Brotwell (1988) -, abriu consideravelmente o espaço para a Síntese Neoclássica. 
em períodos de recessão. Finalmente, teria permitido sair da camisa-de-força representada pela postulação de uma relação negativa entre salário real e emprego, tantas vezes criticada.

Tobin $(1989,1993)$ oferece uma visão peculiar sobre a relação entre a Teoria Geral e o aparato de concorrência imperfeita: Keynes, embora não o tenha explicitado, na verdade supunha concorrência imperfeita. Ou seja, se a concorrência perfeita caracterizava o mundo "clássico", o "ambiente microeconômico" de Keynes era o da concorrência imperfeita. Para demonstrar seu ponto, o autor se apoia no mercado de trabalho - mais especificamente, na hipótese de rigidez nominal de salários. A suposição de concorrência imperfeita seria necessária, para esse autor, para explicar por que os salários nominais não caem na presença de um grande contingente de desempregados:

O fato de que os trabalhadores que estão empregados não queiram reduzir seus salários relativos não impediria que a concorrência dos desempregados do lado de fora dos portões das fábricas provocasse uma redução dos salários de alguma maneira. Keynes pensa estar tratando de mercados concorrenciais, mas na verdade é óbvio que não está. (Tobin, 1989, p. 557 apud Heller, 1996, p. 22).

$O$ fato de que os trabalhadores empregados têm poder de barganha seria o ponto que Keynes teria deixado de explicitar, e mais: "a imperfeição da concorrência nos mercados de trabalho é associada à imperfeição de mercados nos mercados de produtos" (idem). De que forma se dá essa "associação", o autor não explicita. Mas a primeira afirmação, de que Keynes deixou de explicitar a existência de um "poder de barganha" por parte dos trabalhadores empregados, merece um comentário. A leitura do capítulo 19 da Teoria Geral deixa evidente que a hipótese de rigidez de salários nominais não está, de modo algum, na base da explicação de Keynes do desemprego involuntário.

O ponto é, como se disse na seção anterior deste artigo, que mesmo se os trabalhadores empregados aceitassem uma redução dos seus salários, isso não garantiria um aumento do emprego. Portanto, o argumento de Tobin perde o sentido, uma vez que com ou sem poder de barganha por parte dos trabalhadores empregados, há desemprego involuntário. Por quê? Porque estamos falando de uma economia monetária de produção, que pode se encontrar em uma situação em que a demanda por investimento seja insuficiente para gerar pleno emprego de fatores.

Para finalizar esta seção do artigo, vale trazer a interessante posição que Chick (2002) tem acerca da relação entre macroeconomia e microecono- 
mia. Para ela, não é possível haver perfeita consistência entre as esferas macro e microeconômicas, a não ser que se esteja no mundo do equilíbrio geral walrasiano: "(...) a consistência entre uma teoria da tomada de decisão (microeconomia) e o resultado global das decisões não pode, em geral, ser atingida. Algum 'deslize', alguma transigência quanto à consistência interna deve emergir" (Chick, 2002, p. 55).

Ela conclama os pós-keynesianos a não caírem na armadilha de procurarem perfeita consistência entre o que pode ser inferido para um empresário individual e o resultado de suas interações. Faz apelo a uma concepção que é um dos traços marcantes da construção pós-keynesiana: o organicismo. Mesmo que se parta da teoria do agente proprietário de riqueza individual para construir a teoria macroeconômica, o que é em grande parte o procedimento que Keynes utilizou, não é possível considerar estes agentes como isolados, sob pena de perder a compreensão dos fenômenos reais. Nas palavras dela:

O organicismo reconhece que o todo é mais que a soma das partes. A tomada de decisão descentralizada apresenta problemas para a macroeconomia, para os quais não há soluções elegantes fora da economia neoclássica, na qual a elegância é obtida à custa da irrelevância. Há uma escolha: aceitar soluções desordenadas [messy], transigências necessárias; ou tornar-se um economista neoclássico, mantendo a virgindade [...]. (Chick, 2002, p. 65).

\section{Considerações finais}

O ponto fundamental, na Teoria Geral, está no fato de que Keynes caracteriza a economia como sendo uma economia monetária. Não é a estrutura de mercado o determinante dos resultados macroeconômicos keynesianos. O próprio Sawyer, no mesmo artigo em que defende que a incorporação da hipótese de competição imperfeita poderia ter sido benéfica para a Teoria Geral, reconhece que ela não é necessária e vai ao ponto, nisso fazendo coro a Vitória Chick - a essência da mensagem de Keynes era o papel da demanda efetiva na determinação do nível de emprego e renda da economia e, acima de tudo, a natureza da economia como sendo monetária:

O papel da demanda agregada, o foco no ajuste de quantidades para igualar poupança e investimento planejados, etc., surgem em uma economia monetárial financeira, mas não em uma economia de escambo. Desta forma, a distinção importante é entre uma economia monetária e uma de escambo, e não entre uma economia atomista e uma de concorrência imperfeita". (Sawyer, 1995, p. 131). 
Em artigo posterior, com Nina Shapiro (Sawyer; Shapiro, 2002), o autor aprofunda sua reflexão acerca da relação entre estrutura de mercado e a Teoria Geral: o fato de que os agentes decidam em condições de incerteza é o ponto fulcral da teoria de Keynes, e a suposição de que as firmas operam em concorrência imperfeita não é, de modo algum, necessária para "fundamentar" a macroteoria - notadamente, para explicar a ocorrência de desemprego involuntário. A adoção das hipóteses de concorrência perfeita ou imperfeita refletir-se-ia, para os autores, no grau de volatilidade das variáveis macroeconômicas. Em particular, quanto mais "perfeita" a concorrência, maior a instabilidade das condições sobre as quais se assentam as decisões de investimento. Nas palavras deles: "Sob concorrência perfeita, o investimento seria um puro jogo de apostas, sendo o lucro ganho pelos que tivessem feito o investimento 'certo', no tempo 'certo'. O lucro do especulador seria possível, mas não aquele do inovador ou empreendedor" (Sawyer; Shapiro, 2002, p. 51).

Se Keynes utilizou, como suposição para seus resultados, um polipólio competitivo, como quer Chick, ou se lhe faltou coragem para romper com os pressupostos da teoria microeconômica neoclássica, ou ainda se ele não o fez por questões "estratégicas", para facilitar a aceitação de sua teoria, é uma discussão que ainda está aberta. Ele mesmo, confrontado com a sugestão de fazer uso do instrumental de concorrência imperfeita para apoiar seus argumentos, rejeitou claramente essa possibilidade. A ideia de que os resultados da Teoria Geral dependam dessa hipótese, ao nosso ver, apoia-se numa argumentação que deixa de lado elementos essenciais da visão de Keynes.

Davidson (1999) ressalta que um dos significados do termo "geral" da Teoria Geral diz justamente respeito ao fato de esta se apoiar em hipóteses menos restritivas do que as da teoria que Keynes chama de Clássica:

Esta é uma das razões que justificam que eu chame minha teoria de Teoria Geral Uma vez que se baseia em hipótese menos restritivas, é também mais facilmente adotada para uma extensa área de circunstâncias diferentes". (Keynes, 1936, apud Davidson, 1999, p. 35, grifo do autor).

A mesma conclusão é atingida quando se considera o capítulo 18 de sua Teoria Geral intitulado "Novo enunciado da Teoria Geral do Emprego", no qual procura "reunir todos os fios do (...) raciocínio" (Keynes, 1988, p. 166). Keynes inicia a exposição de seu modelo identificando os elementos que toma como dados, e deixa evidente que o grau de concorrência não é ne- 
cessariamente o correspondente à competição perfeita (e tampouco à competição imperfeita).

Tomamos como dados a capacidade e a quantidade de mão de obra disponivel, a qualidade e quantidade do equipamento disponivel, o estado da técnica, o grau de concorrência (...). Isso não significa que suponhamos constantes tais fatores, mas simplesmente que, neste instante e neste contexto, nos abstemos de analisar ou mesmo de levar em consideração as consequências de suas variações (Keynes, 1988, p. 16, grifo nosso).

Note-se que o esforço de se perguntar que tipo de estrutura de mercado pode ser compatível com a macroeconomia keynesiana - e, particularmente, com a ocorrência do desemprego involuntário - pode ser interessante, mas pensar que a macroeconomia necessite de "fundamentos microeconômicos", entendidos como a especificação da estrutura de mercado, nos parece esvaziar o próprio sentido de desemprego involuntário: um fenômeno social, macroeconômico, que decorre das decisões dos proprietários de riqueza quanto à forma de alocação e acumulação desta riqueza - qualquer que seja a estrutura de mercado.

No entanto, fica a ressalva de que o aparato analítico de Keynes é absolutamente incompatível com a abordagem marginalista, e que, ao não explicitar esse ponto fundamental e não enfrentar, ou ao menos reconhecer, os desafios teóricos advindos dessa incompatibilidade, o autor fragilizou sua posição e deixou brechas para os desdobramentos posteriores no âmbito do mainstream da teoria macroeconômica. Nas leituras da Teoria Geral efetuadas pelo mainstream keynesiano, retirou-se a teoria da tomada de decisão do agente capitalista individual, sobre a qual se assentava a macroeconomia de Keynes $\neg-$ um proprietário de riqueza que toma suas decisões em um ambiente de incerteza, e que, para tanto, constrói convenções que somente podem ser compreendidas numa perspectiva organicista. A partir de então, abriu-se espaço para as várias tentativas de "microfundamentar" a macroeconomia keynesiana. Mas, para o mainstream keynesiano, a "microeconomia", chamada a "fundamentar a macroeconomia" restringe-se ao campo da atuação de agentes representativos ofertantes e demandantes de mercadorias, dotados de racionalidade substantiva e funções-objetivo previamente especificadas, atuando em ambiente caracterizado ou não por "falhas de mercado". 


\section{Referências}

ASIMAKOPOLUS, A. Kalecki and Keynes: their correspondence. History of Political Economy, n. 22, p. 50-63, 1990.

BROTWELL, J. F. The General Theory after fifty years - why are we not all keynesian now? In: HILLARD, J. (Ed.) J. M. Keynes in retrospect. Aldershot: Edward Elgard, 1988.

CHICK, V. Keynes's theory of investment: a necessary compromise. In: DOW, S. C.; HILLARD, J. Keynes, uncertainty and the global economy: beyond Keynes, v. 2. Cheltenham (UK) and Northampton, MA (USA): Edward Elgard, 2002, p. 55-67.

CHICK, V. Macroeoconomics after Keynes - a reconsideration of the General Theory. Cambridge, Ma: The MIT Press, 1983.

DAVIDSON, P. Post Keynesian macroeconomic theory: a foundation for successful economic policies for the twenty-first century. Aldershot: Edward Edgard, 1994.

DAVIDSON, P. Post Keynesian employment analysis and the macroeconomics of OECD unemployment. The Economic Journal, v. 108, p. 817-831, may 1998.

DAVIDSON, P. Colocando as evidências em ordem: macroeconomia de Keynes versus velho e novo keynesianismo. In: LIMA, G. T; SICSÚ, J.; PAULA, L. F. de (Eds.). Macroeconomia Moderna: Keynes e a economia contemporânea. Rio de Janeiro: Editora Campus, 1999. p. 35-64.

DUNLOP, J. G. The movement of real and money wage rates. The Economic Journal, sep. 1938.

HELLER, C. Oligopólio e progresso técnico no pensamento de Joan Robinson. Campinas: UNICAMP. IE, 1996 (Tese, Doutorado em Ciências Econômicas).

KAHN, R. The Relation of home investment to employment. The Economic Journal, jun. 1931.

KAHN, R. The Economics of the short period. London: Macmillan, 1989.

KALECKI, M. Some remarks on Keynes's theory. In: OSIATYNSKI, J. Collected work of Michal Kalecki, v. 1, Oxford: Clarendon Press, 1990, p. 223-232.

KALECKI, M. A Theorem of Technical Progress. In: OSIATYNSKI, J. Collected Work of Michal Kalecki, v. 2, Oxford: Clarendon Press, 1991, p. 107-116.

KALECKI, M. The determinants of the distribution of the national income. Econometrica, apr., 1938.

KEYNES, J. M, The collected writings of John Maynard Keynes, defense and development. v. 14. London: MacMillan, 1973a.

KEYNES, J. M. Relative movements of real wages and output. The Collected Writings of John Maynard Keynes, v. 7, apêndice. London: MacMillan, $1973 b$.

KEYNES, J. M. A Teoria geral do juro, da moeda e do emprego. São Paulo: Abril Cultural, 1988.

KEYNES, J. M. The collected writings of John Maynard Keynes. The general theory and after: preparation, v. 13, London: MacMillan, 1973c.

KEYNES, J. M. The collected writings of John Maynard Keynes, v. 12, London: MacMillan 1983.

KEYNES, J. M. The collected writings of John Maynard Keynes, v. 29, London: MacMillan, 1979.

LAVOIE, M. Post Keynesian Economics: New Foundations. Cheltenham, UK and Massachu- 
setts, USA: Edward Elgar, 2014.

MARRIS, R. Yes, Mrs. Robinson! - The General Theory and imperfect competition. In: HARCOURT, G. C.; RIACH, P. A. (Eds.) A "second edition" of the General Theory. London and N.Y: Routledge, 1997. p. 52-82.

PIGOU, A. C. The theory of unemployment. Abingdon: Frank Cass and Company Limited, 1933.

ROBINSON, J. The economics of imperfect competition. London: Macmillan, 1969.

SARDONI, C. Prices, expectation and investment: a critical assessment of Keynes's marginal efficiency of capital. In: PRESSMAN, S.; SMITHIN, J. (Eds.) The Malvern conference ten years on. Abingdon: Routledge, 1996. p. 93-109.

SAWYER, M. C. Unemployment, imperfect competition and macroeconomics - essays in the post keynesian tradition. Aldershot: Edward Elgar, 1995.

SAWYER, M. C.; SHAPIRO, N. Market structure, uncertainty and unemployment. In: DOW, S. C.; HILLARD, J. Keynes, uncertainty and the global economy. Cheltenham (UK) and Northampton, MA (USA): Edward Elgard, 2002. p. 45-54.

TOBIN, J. Testimony: an interview. In: FEIWELL (Ed.). Joan Robinson and modern economic theory. London: Macmillan, 1989.

TOBIN, J. Price flexibility and output stability: an old Keynesian view. Journal of Economic Perspectives, v. 7, n. 1, p. 45-65, 1993.

TORR, C.S.W. The Distinction Between an Entrepreneur Economy and a Co-operativa Economy (Review Note), Die Suis-Afrikaanse Tydskril vir Ekonomie, v.48, n.4, p.429-434, 1980.

\section{Sobre a autora}

Adriana Nunes Ferreira - adrinf@gmail.com

Instituto de Economia da Unicamp, Campinas, SP.

\section{Sobre o artigo}

Recebido em 06 de outubro de 2014. Aprovado em 30 de setembro de 2016. 